\title{
Exploring a new Division 1 football program on a university campus
}

\section{An application of collaborative action research in higher education}

\author{
Amanda Greene and Kason O’Neil \\ Department of Sport, Exercise, Recreation and Kinesiology, \\ East Tennessee State University, Johnson City, Tennessee, USA, and \\ Gary Lhotksy \\ West Virginia University, Morgantown, \\ West Virginia, USA
}

\begin{abstract}
Purpose - This paper is an account of collaborative action-based research that centered on a new NCAA Division I football program at a regional southeastern university, and the positive impacts the collaboration had on the multiple stakeholders involved in the research, which were the university's sport management faculty, the athletic department, and sport management students. The paper aims to discuss these issues.

Design/methodology/approach - During the action research, these stakeholders moved through a cyclical process that involved reflection, planning, action, and evaluation. Through the action-based cyclical process that was utilized, each of these stakeholders were able to learn, adapt, participate, and make positive change.

Findings - Positive change occurred with the athletic department's marketing efforts and game day operations, opportunities for sport management students to participate and learn, and development of relationships between two departments.

Research limitations/implications - The cyclical nature of this research model often leads to original hypotheses and research foci to be highly altered during various stages. Another limitation within collaborative action research can be the breakdown in communication among the many parties involved in carrying out this type of research.

Practical implications - While the significance of this study was initially to capture fan information surrounding a new NCAA Division I football program, the stakeholders quickly realized that the action-based research study had more to offer than producing marketing reports for the university athletic department. Inclusion of the students as equal stakeholders in this project proved vital to student learning and involvement. Having the students play such an important role throughout each cycle of the project allowed for additional networking outside the classrooms with potential employers, as well as in-depth discussions and involvement in the classroom when synthesizing and disseminating the marketing information that had been gathered.
\end{abstract}

(c) Amanda Greene, Kason O'Neil and Gary Lhotksy. Published in Journal of Work-Applied Management. Published by Emerald Publishing Limited. This article is published under the Creative Commons Attribution (CC BY 4.0) licence. Anyone may reproduce, distribute, translate and create derivative works of this article (for both commercial \& non-commercial purposes), subject to full attribution to the original publication and authors. The full terms of this licence may be seen at http://creativecommons.org/licenses/ by/4.0/legalcode

Funding: This research received no specific grant from any funding agency in the public, commercial, or not-for-profit sectors.

The authors would like to thank the other teams involved who collaborated to make this research a success. Special appreciation goes to the students who volunteered their time to collect data for the project. Should there be any comments/reactions you wish to share, please bring them to the interactive portion (Reader Responses column) of the website: http://arj.sagepub.com
Exploring a new Division 1 football program

Received 20 December 2016 Revised 20 March 2017 12 May 2017 Accepted 31 May 2017 
$\underset{9,1}{\text { JWAM }}$

6

Originality/value - The collaboration between two separate departments within a higher education institution was vital to the overall success of the research project. The overall intent of this paper is to provide a practical approach to collaboration among individuals working in different departments of an organization, as the findings from this research project revealed the overall success of the project was only possible through the collaborative effort and joining resources, abilities, areas of expertise, and capabilities.

Keywords Higher education, Collaboration, Football, Sport marketing, Action research

Paper type Viewpoint

\section{Introduction}

The academic field of sport management has always thrived on its ability to create authentic learning experiences and produce professionals who are devoted to interdependent relationships between the community and various sporting organizations (Hoye et al., 2015). As a result of authenticity inherently built in to the world of sports management, it becomes imperative that research in the field revolves around action, participation, and human interaction (Morse and McEvoy, 2014). Specifically, sport management's "subject matter is comprised of human processes and experiences that are reflected in thoughts, emotions, and purposeful behaviors which are shaped by the dynamic flux of social life" (Brustad, 2009, p. 112). Being in such a human-driven field, it is vital that continual examination explores the impact human actions and perceptions have on management and administration of sport (Morse and McEvoy, 2014). Due to the fact that human interactions are the cornerstone of university sport management education, it becomes vital to make sure sports management students are provided opportunities for authentic learning experiences that focus on student involvement and diverse human interactions (Astin, 1999; Braxton et al., 2000).

Throughout the action research process of this study, the research team utilized a cyclical process of reflection, planning, action, and observation to obtain information about fan behavior (Bradbury-Huang, 2010). Human interactions and collaborative experiences drove the methodology of this study, with the intention of data collected to ultimately influence participation, action initiatives, and change related to a new university football program in the southeastern region of the USA. The faculty designed the project in a way that student learning would occur in a collaborative way through student-student interaction, student-faculty interaction, as well as networking with professionals in their field with in the athletic department. Thus, the purpose of this paper is to bring attention to the execution of a collaborative action research study that focused on fan behavior associated with new NCAA Division I football program; examine the impact the collaboration had on the three diverse stakeholders involved in the process (sport management faculty, sport management students, and the university athletic department); and to specifically highlight the benefits sports management students derived from being active, and equal, contributors to the research process throughout the study.

This study offers a unique perspective and insight to sport management faculty, university athletic department employees, as well as sport management students; as each stakeholder derived very different experiences and knowledge as a result of this collaborative action research study. University athletic departments and sport management programs do not always work together, thus this study provides an example of the effectiveness and feasibility of such collaboration between the parties.

\section{Action research}

One research methodology that exemplifies the "learn-by-doing" principles in sport management is that of action research. Action research is a systematic approach toward the investigation of a particular event, occurrence, or experience that brings about some form of change (Stringer, 2007; Bradbury-Huang, 2010). "Unlike traditional experimental/scientific 
research that looks for generalizable explanations that might be applied to all contexts, action research focuses on specific situations and localized solutions" (Stringer, 2007, p. 1). Researchers can use action research to approach authentic experiences, explore new innovations, and find meaning in diverse social science topics. Thus, the underlining emphasis of action research is that understanding is only possible through action, and that practice is what legitimizes theory (Bradbury-Huang, 2010).

Action research is widely accepted as a collaborative approach toward systematically investigating and inquiring, and then taking action toward a specific problem (Stringer, 2007; Kemmis and McTaggart, 1992). The model of action research is often referred to as a series of action cycles. The four major components of an action cycle are: formulating a plan based on a need or a problem, acting and implementing on the agreed upon plan, observing and collecting data on the particular phenomena, and reflecting on the process for future revisions (see Figure 1). Researchers use this cyclical process to explore the details of particular phenomena, or action, through observation, reflection, and action (Thathong et al., 2009).

Much of the action research literature supports the notion that this bottom-up style of research inherently has complications along the way. As is the case in other linear research models, action research is not always a clean process that allows for step-by-step navigation (Kemmis and McTaggart, 1992). Researchers will "find themselves working backward through the routines, repeating processes, revising procedures, rethinking interpretations, leapfrogging steps or stages, and sometimes making radical changes in direction" (Stringer, 2007, p. 9). Though often times a complex process, action research is an authentic and self-reflective way for individuals to formulate effective solutions to numerous social science problems.

Another major principle within action research is that of social and personal interactions (Brydon-Miller et al., 2003). Respect among individual thoughts, ideas, and reflections in the pursuit for knowledge and information is a major commonality among action researchers. "Working collaboratively with others leads not only to community and organizational changes, but also to personal changes in the action researcher" (Brydon-Miller et al., 2003, p. 14). Much of the action research literature emphasizes quality social and personal interactions that stem from the following:

- establishing and maintaining positive working relationships that promote equity, encourage collaborative and creative efforts, and are sensitive to each other's thoughts and beliefs;

- communication among all parties that facilitates understanding, truth, and sincerity toward attainment of the overall group objectives;

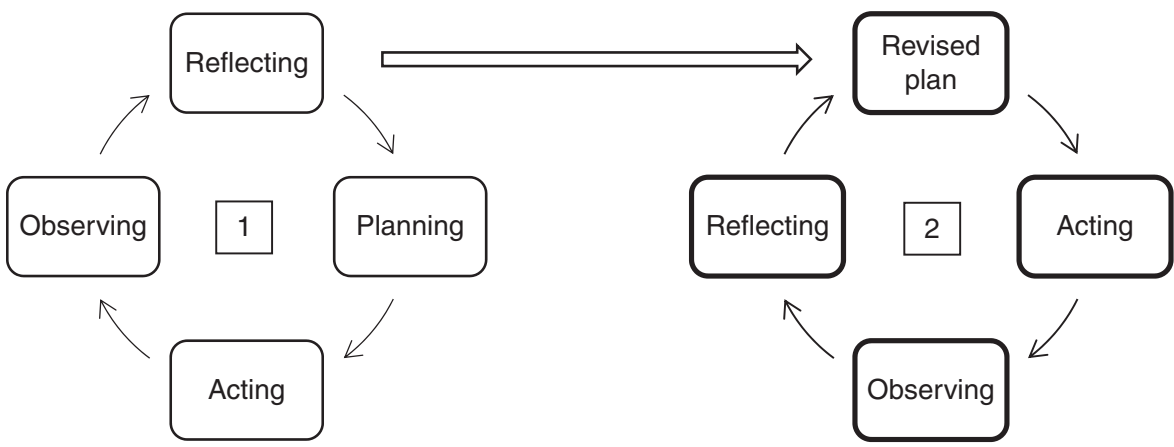

Source: Adapted from Stringer (2007), Kemmis and McTaggart (1992), Zuber-Skerritt (2001)
Exploring a new Division 1 football program 
$\underset{9,1}{\text { JWAM }}$

- active engagement and participation in all aspects of the research process; and

- inclusion of all parties in the research process to seek maximization of involvement (Stringer, 2007; Brydon-Miller et al., 2003; Kemmis and McTaggart, 1992).

\section{Limitations}

Since action-based research is focused on a systematic approach that is designed to bring about some form of change, this type of research has inherent limitations. One such limitation is the unforeseen circumstances that arise during studies employing this research model. The cyclical nature of this research model often leads to original hypotheses and research foci to be highly altered during various stages. Another limitation within collaborative action research can be the breakdown in communication among the many parties involved in carrying out this type of research. It is important to note the limitations, as researchers are not always involved in research that is constantly evolving for the purpose of creating change.

In an effort to address these limitations, research teams need to be proactive in planning and communication efforts. Unforeseen circumstances cannot be forecasted in action research and plans may need to change immediately. One strategy to combat this issue would be for the research team to establish an open line of communication as well as a hierarchy of decision making among the collaborating parties, in an effort to expedite change quickly. Communication is often an issue in action research, especially when multiple parties are collaborating on one study. Establishing well-defined roles for each party involved would allow for more direct communication with the appropriate parties and potentially eliminate communication errors.

\section{A higher education application of action research}

Many years in the making, the Fall of 2015 was the inaugural season for a new NCAA Division I football program at (disclosed university name). Discussions regarding the new football program and research collaboration between the athletic department and the sport management program began in the Summer of 2015, just prior to the first season. The research team included sport management faculty and students as well as the university athletic department.

The research team engaged in collaborative action-based research for this project, which involved moving through a cyclical process that involved reflection, planning, action, and evaluation within two major phases. Phase I of this project emphasized data collection of attending fan demographics, geographics, and psychographics. This data were collected at each home football game within the inaugural season. Each cycle of the action-based process allowed for ongoing learning experiences for each party, with continual adjustments needed along the way. The change that resulted from the learning and research process positively impacted the sport management faculty, university athletic department, and sport management students.

Though data collection of attending fans (demographics, geographics, and psychographics) was the emphasis of the research agenda at the start of the process, it became evident early on to the research team that there was an opportunity, and need, for a second research agenda (i.e. Phase II). The decision to have an extension of the research agenda came as a direct result of the action research process. Initial results from Phase I revealed fan needs that could immediately be addressed in an effort to increase overall game day satisfaction. These needs prompted the research team to launch a more in-depth survey about fan perceptions of game day and overall satisfaction in their game day experiences. Phase II of the research agenda included an online survey that reached beyond the attending home game fan base (i.e. Phase I), and surveyed fan experiences of season ticket holders and 
consumers of any of the university's athletic programs. The action-based cyclical research approach played an important role in revealing the need for a Phase II.

Success for this collaborative action research was delimited by the authors in the following areas: in total, 991 land-based surveys were collected during tailgating at home football games; game day data analysis and charts provided immediate information following each home game, information that was used by local athletic administration to enhance efforts to recruit fans in future games; sport management students had opportunities to become equal party members of the research team, gaining valuable experience in planning, data collecting, and data analysis; research materials were used in the sports management classroom to further engage students in the research process, as well as foster discussion about fan behaviors in a context that was relevant to their own personal community; an overall improvement of working relationships within the two departments; immediate game day operation information for the sport marketing team to review; and the football coaching staff were provided access to post-game data regarding their fan base demographics and overall support of the new football program.

\section{Student involvement theory applied to higher education}

A secondary focus of this action research project was increasing student involvement, inside and outside the classroom. Many studies have been conducted on the relationship between student learning and level of student involvement. These studies suggest that the more involved in the academic experience the students are, the more likely they are to achieve greater academic success and satisfaction with the university (Astin, 1999; Terenzini et al., 1994).

Astin (1999) defined involvement as both physical and psychological energy students devote to their academic disciplines. Student involvement has been proven to foster relationships, create more effective educational programming, and increase retention at universities. The classroom takes on an important role in regard to the actions listed above. Specifically, the direct influence of classroom-based academic experiences of students on withdrawal decisions (Nora et al., 1996).

The design of this project was not only to collect information about the fans of a new football program, but to also increase student involvement through action-based research. From being involved in the planning process, to information gathering and surveying, in addition to data analysis and creation of reports, the sport management students were vital to the success of this project.

\section{Methods}

Throughout the research process, the team utilized each of the four aspects of an action research cycle (planning, acting, observing, and reflecting). Phase I utilized the action research cycle, and as a result, changes were implemented along the way to aid in the success of the overall research project, and demonstrating a need to employ a Phase II of the project (i.e. online survey). This section will detail how the research team was able to utilize the four-part cycle to achieve the level of success desired for each party.

\section{Phase I: survey of fan perception of new football program}

Reflection. For this research project, it was imperative that more than one unit come together in order for sport management to fulfill their vision of student involvement, learning, and change through action research of the new D1 football program. It was also vital that the athletic department engaged in collaboration in order to fulfill their visions of creating the surveys, collecting data at each home game, and having immediate access to the data after each data collection series. When both parties laid out their goals of this project, a process of 
JWAM

9,1

dividing responsibilities occurred. It was through the reflection stages in the action-based research model that both departments concluded this would be a fluid project with constant adjustment and change throughout the research and data collection process.

In the initial reflection stage, both departments shared goals and learning objectives that each aspired to derive from this research project. Specifically, the sport management faculty was seeking a rich action-based research opportunity for their students to engage in and learn from. The sport management faculty was also seeking involvement in this research project to add to the overall body of knowledge in the field of sport management; answering the question of how action-based research results in adaptation, learning, and change, both within the sport management department and athletic department. In comparison, the university athletic department approached the initial reflection process with an agenda that sought specific data on fan perceptions of their new football program. From a sport business perspective, they looked at this action-based research project as a way to obtain important information about the new football program's fan base and other demographic data that would aid in marketing efforts, as well as overall program identification for the first season. The athletic department sought information about fan identity, economic benefits, loyalty to the new program, and overall community support. Though both departments approached the early stages of the process with different objectives, a partnership with pooled ideas and resources would ultimately lead to efforts that would be found beneficial for all parties involved.

\section{Planning}

Survey creation. Both departments met on several occasions to decide on a list of survey items that would best address the desired information. Due to the unique research collaboration opportunity present with the creation of a new football program, both departments submitted an equal number of questions they regarded as necessary for the survey, some of which came directly from sport management student suggestions. Additional meetings resulted in decreasing the number of questions and finalizing the survey, an instrument aimed at seeking fan demographic information and perception of fan identity.

The research team solicited sport management students to help collect data during tailgating of all home games in the inaugural season using iPads with built-in survey software. This presented a unique opportunity for sport management students to apply what they had learned about action-based research in a professional setting, as well as gain experience in data collection, face-to-face solicitation, and professionalism. During the initial planning stage, incentives were considered for participants in the study (e.g. fan gear), but overlooked for student volunteers collecting the data. This observation led to future action that added incentives for the sport management student data collectors as a means of motivation.

\section{Action and observation}

Research software. The sport management program used iPad tablets available for data collection as well as access to online research software that would allow for quick and easy upload from the tablets to statistical software hosted on faculty computers. Managing of all the land-based data, as well as data transfer, was through the iSurvey software by the sport management faculty. Graduate sport management students were able to learn the capabilities of this software and start initial data analysis and creation of reports for the athletic department.

Training volunteers. Training the student volunteers by sports management faculty occurred multiple times as the volunteer list of students did not remain the same throughout 
the season. Students were brought into a classroom setting and given a brief overview of the research project and its importance to the university, athletics, sport management, and to them as students. Then students were each given a tablet with the survey uploaded. Sport management faculty went through each question of the survey to ensure all were aware of how the questions were to be asked and how to navigate in the tablet.

Data collection. Permission about collecting data outside the stadium was obtained through the stadium manager, since the university played home games off-campus at a local high school stadium while the campus stadium was being built. Student data collectors were informed that they could only collect in the designated tailgating areas. Data collection would start approximately two hours before the game and students were given a goal of no less than 20 completed surveys for undergraduate students and no less than 25 completed surveys for graduate students.

Retrieving data. After the data had been collected on the ten tablets, the faculty member overseeing the project would then immediately upload data to the laptop. The iSurvey program had many features that the faculty used to help analyze data for the sport management department, athletic department, and sport management students. A few of those features included charting of data, sorting of data, and uploading data from the website to other statistical programs such as SPSS or Excel.

\section{Observation and further reflection}

Data analysis/report data. The day after a home football game the faculty member used the iSurvey software to produce a visual and numerical data summary. The charts and figures provided visual reports of each survey item, information that was deemed highly beneficial for both the athletic department and faculty members using the data in the classroom. Faculty also used the iSurvey software to sort longitudinal data across all home games and to seek trends within the data. Athletics then used this information to produce presentations for the athletic directors, marketing teams, and ticketing offices. Once the athletic department performed their data analysis, reports were then re-sent to the sport management faculty for review and discussion. Students were involved in data analysis in the classroom setting. This allowed for critical thinking, information seeking, and application of content; in an effort to produce valid and relevant reports.

After the completion of the football season, a meeting between sport management faculties, selected sports management students, and representatives from the athletic department devised a plan that included a follow-up longitudinal study for the succeeding football seasons. A plan was constructed to continue the partnership between the two departments with each providing similar responsibilities and duties.

\section{Phase II: online survey of fan experiences}

Reflection and planning. Throughout the process of data analysis, it became evident to both departments that there was a need for an implementation of a Phase II of the research agenda. This required the creation of a second survey that would be administered online and would reach beyond game day attendees. This survey focused on the fan experience and overall satisfaction with the game day experience. The athletic department utilized its consumer database to send out e-mails to the university athletic supporters, alumni of the athletic department, season ticket holders, and current ticket holders.

Action and observation. The Phase II survey was created in SurveyMonkey through the university athletic department. The athletic department solicited any fan or alumni on their e-mail registry to complete a survey about fan experience. These e-mail blasts were sent three times throughout the inaugural season; after the initial game, after homecoming, and after the conclusion of the football season. The research team received 455 completed
Exploring a new Division 1 football program 

$\underset{9,1}{\text { JWAM }}$

surveys for Phase II. Information from this data set was able to be used by the university athletic department to analyze fan experiences and seek trends, in order to create positive change in upcoming seasons.

\section{Results of the action research process}

This action-based research study impacted three main groups of stakeholders of this university. Utilization of the action research cyclical methodology allowed this study to change and evolve throughout the process. The ability to revise the plan, and immediately put revised changes into action allowed for greater learning outcomes for each department. The type of impact varied greatly among the groups, but each resulted in being positively affected by the collaborative efforts that took place throughout this action-based research study of a new D1 football program. The three main groups impacted were sport management faculty, sport management students (both graduate and undergraduate), and the university athletic department. Strategically utilizing strengths and resources from each of these three groups allowed the research team to successfully collect data at each home game. This effort resulted in a sample size of 991 for the land-based survey, and 455 for the online survey. Without the collaboration of all three groups this study would not have been as successful and would not have had to opportunity to impact such a large number of stakeholders at this university.

Action research impact on sports management faculty. The collaborative nature of this study, encompassed with the action-based research method, allowed the sport management faculty to gain valuable experiences in several areas. First, the faculty was charged with the creation of the research tool, which initially was one land-based survey. Throughout the cyclical research process, the research team discovered the need for a second survey that was administered online. The land-based survey focused largely on demographics, geographics, and psychographics, with the online survey focusing on fan perception. The creation of the surveys were learning experiences, as both the sport management faculty and the athletic department worked together to create research tools that fit the needs of both parties. Through the action research model, the sport management faculty was able to revise the initial plan of one survey and saw the need for additional information to be collected. Specifically, the sport management faculty was more interested in the fan base and fan perceptions, while the athletic department was initially more interested in the demographic information. Working through each of the action research stages, the research team was able to make adjustments that resulted in additional learning and positive change. The information produced from the online survey was of great use to the sport management faculty both in the classroom and from a professional aspect.

The faculty also arranged the methodology of collecting the land-based surveys on tablets. One of the greatest benefits derived from the faculty was in the initial phases of the research study when programming the tablets and the education of a new research survey platform. Faculty had to install and learn a software program which neither departments had previous exposure, and then program to ten different tablets and a laptop. Upon successfully completing this task, the faculty felt more confident in administering and collecting data using the tablets. This process enabled sport management faculty to learn a new software program and offered a new up-to-date method of data collection in future research projects.

A third impact of this study had on the sport management faculty was involvement across campus. Through this collaborative effort the faculty became more active within the athletic department, attending meetings, brainstorming future projects, and learning of internships and volunteer opportunities within the athletic department. The faculty began to see the importance of these two departments working together on sport-related topics 
outside of research agendas. It was through this impact, that the faculty was then able to bring in a third party to collaborate, the sport management students. Through relationships that were built between the sport management and the athletic departments, opportunities began to arise for sport management students seeking to gain experience in the field of collegiate athletics.

Action research impact on sports management students. Both the graduate and undergraduate students were positively impacted by the collaboration that took place between the two departments. One of the greatest benefits resulted from the action-based research model that allowed the students to actively engage with both departments in the execution of the research project. The students were able to foster relationships with individuals in the athletic department, resulting in administration from the athletic department guest lecturing in the classrooms. These relationships offered additional opportunities for the students to volunteer at the football games, as well as engage in semester-long internships within the athletic offices. Some of the responsibilities the sport management students engaged in were game day operations, marketing, ticket sales, and promotion. Through the collaboration of departments to execute a research project, an added benefit of providing students with invaluable experience had a profound impact on the sport management program. The students were learning by hands-on experience in their chosen field and were given the opportunity to handle responsibility in the professional field of sport management.

Faculty specifically designed parts of this study with student involvement and learning in mind. Faculty knew the importance of involvement and engagement both inside and outside the classroom setting, and therefore offered multiple avenues for these learning opportunities to occur. Some examples of student involvement were review of the survey and in-class discussions, actively collecting data and working home game events, engagement in data analysis and relevant information for producing reports, and collaborative opportunities with athletics from relationships that were formed throughout the process.

A total of 31 students, both graduate and undergraduate, signed up to aid in this research process. The sport management faculty surveyed each of the sports management student involved to gain a better understanding of overall impact this research project had on each volunteer. Results from the sports management surveys revealed that the students benefited in many ways from this experience. A list of the student survey questions and results can be found in Table I.

Table I indicates that learning outcomes and valuable experiences were derived from student involvement in this research project. These results also specially align with literature supporting experiential learning theory and student involvement theory, in that learning occurs in students when they are actively learning (Astin, 1999; Kruger et al., 2015; Kolb and Kolb, 2011, 2005). Qualitative feedback from the sports management student displayed that they found this opportunity: provided a unique setting to learning about research in sport management; experience with data collection and market research; brought about additional volunteer opportunities in the athletic department; and they felt this was a quality research experience to add to their professional resume. This is of particular importance as literature suggests that research in the sport business industry is on the rise, and students with research experience are more likely to get hired by sport agencies (Morgan, 2015; Madan and Teitge, 2013).

Action research impact on university athletic department. The athletic department also derived many benefits from this research collaboration. First, they gained instant access to reports and files that included all the weekly data collected at each home game. One way this information was utilized was through visual reports created for use in staff meetings following each home game. Through the collaborative work between the programs, sport
Exploring a new Division 1 football program 
$\underset{9,1}{\text { JWAM }}$

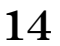

(1) I feel exposure to this research opportunity increased my knowledge of the overall research process in sport

1

(2) This was a productive way to learn about sport research outside of the classroom setting

2
SD

(3) This volunteer opportunity helped me become more confident approaching fans and asking for participation

(4) Utilizing technology made this experience more exciting by collecting data on tables

(5) Incentives that were offered to volunteers motivated me to participate

(6) This volunteer opportunity opened doors with Athletics for additional work experience

(7) Overall, I feel this is an experience I can add to my resume and will be beneficial as I seek a job in the field of sport

management faculty were able to send the initial data analysis and quick charts immediately following each home game. This part of the process allowed this information to be available to the university athletic department before they debriefed each football game day. Obtaining this information in a timely manner was valuable to the university athletic department so change could be implemented, if needed, before the following home game.

A second benefit of this collaborative process to athletics was the type of information being collected. The information the sport management students were collecting, via the surveys, and the amount of surveys the students were collecting, provided adequate amounts of information for the athletic department to be able to identify trends and make change if needed. For example, the survey results indicated a high percentage of families with children in attendance of the first home game. The sport marketing team, a sub-division within the athletic department, immediately implemented more kid friendly activities in the tailgating areas for the remaining home games in order to accommodate this fan base. Without immediate access to the data, the athletic department may not have been able to make this adjustment for this large fan base.

A third benefit to the athletic department is the implications this relevant data will provide for the football program in the future. As stated by the university athletic director, (disclosed athletic director name), "I can't tell you how much the surveys that you and your students developed and implemented for our home football games have helped us plan for the future. By mining relevant data, you gave us the ability to understand our fan base and much better service them while also developing strategies to maximize revenues. I appreciate the sport management department's enthusiasm for collaboration and think there will be many opportunities in the future to work together. Thanks to you and all your students."

\section{Complications throughout the process}

As with most action research projects, unforeseen circumstances arise. This study was no different as researchers thoroughly examined each step of the cyclical process and made adjustments when needed. One of the early hurdles was initial student involvement. 
Student involvement theories had been researched prior to the study and the faculty was confident that this project would offer valuable experiences to the students. However, after the initial excitement of the project, student volunteers and classroom discussions were insufficient. The faculty better educated the sport management students on the type of learning experiences they would gain by being active participants both inside and outside the classroom. This approach was successful in obtaining student involvement.

Another complication of this project that was overcome was application for the graduate students who were meeting online for course work. To combat this issue, select graduate students were asked to visit an undergraduate marketing class to aid in information synthesizing and lead discussions with undergraduate students about the marketing information they had collected.

\section{Discussion and conclusions}

As evident by the results discussed above, together the collaboration efforts and action-based research method greatly influenced the success of this study. The authors distinguished the success of this methodological approach among the three groups that worked collaboratively throughout this process: the university athletic department, sport management program, and sport management students. Through the action-based cyclical process that was utilized, each of these stakeholders were able to learn, adapt, participate, and make positive change. Learning and change were not isolated to the athletic department as one might assume, rather all of the groups involved were positively impacted by the action-based research. Each of the following areas experienced change as a result of this study: the athletic department's marketing efforts and game day operations, opportunities for sport management students to participate and learn, and development of relationships between two departments.

One of the most important findings from this collaborative study was the increased student involvement and opportunities presented which allowed for deeper learning of sport marketing content. Astin states that student involvement is a key component to student success at a university. Studies have shown that the greater the student involvement, both inside and outside the classroom; the more likely learning outcomes were obtained and student understanding of the content was greater (Braxton et al., 2000; Tinto, 1998). Faculty found this project to offer multiple opportunities for student involvement, including increased student-student interactions, student-faculty interactions, and student-professionals interactions. These opportunities would not have been afforded to the students without the collaborative nature of this project.

While the significance of this study was initially to capture fan information surrounding a new NCAA Division I football program, the stakeholders quickly realized the action-based research study had more to offer than producing marketing reports for the university athletic department. Inclusion of the students as equal stakeholders in this project proved vital to student learning and involvement. Having the students play such an important role throughout each cycle of the project allowed for additional networking outside the classrooms with potential employers, as well as in-depth discussions and involvement in the classroom when synthesizing and disseminating the marketing information that had been gathered. Braxton et al. (2011) state that providing active learning experiences for students will deepen not only their learning of the material but will also deepen their sense of community and connection with the University. Through this action-based research project, the faculty is confident that they provided such an experience to the students.

In conclusion, the results from this study fall in line with the previous research relating to the importance of collaborative action research in the field of sport management (Morse and McEvoy, 2014; Stringer, 2007). Brustad (2009) states, sport management's
Exploring a new Division 1 football program 
JWAM

9,1

"subject matter is comprised of human processes and experiences that are reflected in thoughts, emotions, and purposeful behaviors which are shaped by the dynamic flux of social life" (p. 112). The research team utilized the action-based cyclical process to address the human processes and experiences that influence and impact the study of such a human-driven field. The impacts of this study were positive and created a research environment full of learning, participation, and change. Implications from this study include a more broad understanding of how multiple organizations can work together in an effort to more efficiently meet the needs of each stakeholder. While the present study focused on a university setting, the information presented can be transferred to many sport management organizations in an effort to encourage collaboration and action research to create change within organizations.

\section{References}

Astin, A.W. (1999), "Student involvement: a developmental theory for higher education", Journal of College Student Development, Vol. 40 No. 5, pp. 518-529.

Bradbury-Huang, H. (2010), "What is good action research? Why the resurgent interest?", Action Research, Vol. 8 No. 1, pp. 93-109, doi: 10.1177/1476750310362435.

Braxton, J., Hirschy, A. and McClendon, S. (2011), "Understanding and reducing college student departure”, ASHE-ERIC Higher Education Report, Vol. 30 No. 3.

Braxton, J., Milem, J. and Sullivan, A. (2000), "The influence of active learning on the college student departure process: toward a revision of Tinto's theory", The Journal of Higher Education, Vol. 71 No. 5, pp. 569-590.

Brustad, R.J. (2009), "Validity in context - qualitative research issues in sport and exercise studies: a response to John Smith", Qualitative Research in Sport and Exercise, Vol. 1 No. 2, pp. 112-115.

Brydon-Miller, M., Greenwood, D. and Maguire, P. (2003), "Why action research?", Action Research, Vol. 1 No. 1, pp. 9-28.

Hoye, R., Smith, A.C., Nicholson, M. and Stewart, B. (2015), Sport Management: Principles and Applications, Routledge, New York, NY.

Kemmis, S. and McTaggart, R. (1992), The Action Research Planner, 3rd ed., Deakin University Press, Springer, Singapore; Heidelberg; New York, NY; Dordrecht and London.

Kolb, A. and Kolb, D. (2011), "Experiential learning theory: a dynamic, holistic approach to management learning, education, and development", available at: www.researchgate.net/ publication/267974468_Experiential_Learning_Theory_A_Dynamic_Holistic_Approach_to_ Management_Learning_Education_and_Development?enrichId=rgreq-7060407e-0760-4454acd8-37813eede940\&enrichSource=Y292ZXJQYWd1OzI2Nzk3NDQ2ODtBUzoyMzAyMj10MTA4M DkzNDRAMTQzMTkwMDcwODU5OA\%3D\%3D\&el=1_x_2 (accessed February 22, 2017).

Kolb, A.Y. and Kolb, D.A. (2005), "Learning styles and learning spaces: enhancing experiential learning in higher education", Academy of Management Learning \& Education, Vol. 4 No. 2, pp. 193-212.

Kruger, J., Kruger, D. and Suzuki, R. (2015), “Assessing the effectiveness of experiential learning in a student-run free clinic", Journal of Pedagogy in Health Promotion, Vol. 1 No. 2 pp. 1-4.

Madan, C. and Teitge, B. (2013), "The benefits of undergraduate research: the student's perspective", The Mentor - Journal of Academic Advising, Vol. 1 No. 2, pp. 91-94, available at: https://dus.psu. edu/mentor/2013/05/undergraduate-research-students-perspective/ (accessed February 2016).

Morgan, J. (2015), "An investigation into the engagement of undergraduates in work experience: sport development focus", doctoral dissertation, Cardiff Metropolitan University.

Morse, A. and McEvoy, C.D. (2014), "Qualitative research in sport management: case study as a methodological approach", The Qualitative Report, Vol. 19 No. 31, pp. 1-13. 
Nora, A., Cabrera, A., Hagedorn, L. and Parcarella, E. (1996), "Differential impacts of academic and social experiences on college-related behavioral outcomes verses different ethnic and gender groups at four year institutions”, Research in Higher Education, Vol. 37 No. 4, pp. 427-452.

Stringer, E.T. (2007), Action Research, Sage Publications, Inc., Los Angeles, CA.

Terenzini, L., Rendon, M., Upcraft, L., Millar, S., Allison, K., Gregg, P. and Jalomo, R. (1994), "The transition to college: diverse students, diverse stories", Research in Higher Education, Vol. 35 No. 1, pp. 57-73.

Thathong, K., Thathong, N., Silanoi, L., Pitak, N., Srisuruk, P., Punturat, S. and Chinjumtuk, S. (2009), "An application of the principles of action research in developing teachers' potentiality according to the National Education Act of 1999", Research in Higher Education Journal, Vol. 2 No. 1, pp. 1-16.

Tinto, V. (1998), "Colleges as communities: taking research on student persistence seriously", The Review of Higher Education, Vol. 21 No. 2, pp. 1-8.

Zuber-Skerritt, O. (2001), "Action learning and action research: paradigm, praxis and programs", Effective Change Management through Action Research and Action Learning: Concepts, Perspectives, Processes and Applications, pp. 1-20, available at: https://pdfs.semanticscholar.org/2 3a6/89ad465ddfe212d08e4db3becca58bdbf784.pdf

\section{Corresponding author}

Amanda Greene can be contacted at: greenea@etsu.edu
Exploring a new Division 1 football program

For instructions on how to order reprints of this article, please visit our website: 